\title{
PERAN ARBITRASE ICSID DALAM KERANGKA PENANAMAN MODAL
}

\section{INDONESIA}

\author{
Tri Setiady \\ Univrsitas Wiralodra, Indramayu \\ Email : trisetiady@yahoo.com
}

\begin{abstract}
At present many foreign investment contracts are made by the State subdivisions and State companies on one side with foreign private companies on the other. For countries that want to carry out a lot of business contracts in the field of foreign investment, which of course must provide stimulating incentives for investment, including the provision of supervision of foreign companies, because foreign investment means getting knowledge, experience, technical and managerial fields. The main considerations of foreign investment to carry out business contracts are basically their market expansion, besides the low production costs due to relatively cheaper labor costs, tax-free facilities (tax holidays) and other facilities free of charge by the capital receiving countries ( host states).
\end{abstract}

Keyword :Contracts, Arbitration, ICSID, Foreign Investment

\section{PENDAHULUAN}

Undang-Undang Penanaman Modal yang baru yaitu Undang-Undang Nomor 25 Tahun 2007, yang dapat memberikan jaminan hukum yang cukup memadai, tetapi Negaranegara pemilik modal masih menganggap perlu untuk mengadakan perjanjian-perjanjian yang khusus guna melindungi modal yang ditanam di Negara-negara berkembang. ${ }^{1}$ Hal ini disebabkan karena suatu alasan bahwa dalam bentuk apapun berlakunya suatu aturan, sewaktu-waktu perturan tersebut dapat diubah oleh pemerintah Negara yang bersangkutan. Sedangkan jika diadakan suatu perjanjian internasional baik yang bersifat bilateral maupun multilateral, maka pemerintah Negara berkembang tetap akan terikat oleh kewajiban-kewajiban internasional. $^{2}$

Perjanjian bilateral yang pernah dilakukan oleh pemerintah Indonesia dengan negra-negara investor seperti Amerika Serikat, Jermam, Belgia, Belanda, Norwegia dan Denmark adalah perjanjian jaminan penanaman modal asing atau Investment Guaranty

${ }^{1}$ Sunarjati Hartono, 1972, Beberapa Masalah Transnasional dalam Penanaman Modal asing di Indonesia, Bina Cipta, Bandung, hlm 111.

${ }^{2}$ Ibid, 
Agreements. ${ }^{3}$ Sedangkan perjanjian multilateral yaitu dengan adanya Konvensi Washington $1965^{4}$ yang telah diratifikasi oleh pemerintah Indonesia melalui UndangUndang Nomer 5 Tahun 1968 tentang persetujuan atas Konvesi tersebut. Secara otomotis Pemerintah Indonesia terkait oleh ketentuan-ketentuan Konvensi tersebut, walaupun terhadap yurusdiksi arbitrase ICSID yaitu badan arbitrase yang bibentuk oleh Konvensi tersebut. $^{5}$

Dengan diratifikasinya Konvensi Washington 1965 oleh Undang-Undang Nomor 5 Tahun 1965 sebenarnya tidak ada alasan bagi investor meminta jaminan yang lebih dari Negara penerima modal (host country), karena tindakan pemrintah (Indonesia) terhadap para investor tidak perlu dikhawatirkan lagi. Seperti pernah dilakukan oleh pemerintah Indonesia dalam menasionalisasikan perusahaan tembakau Belanda, yang berakhir dengan kemenangan Republik Indonesia karena digugat melalui pengadilan asing yang tidak memiliki kewenangan untuk menguguat sebuah Negara berdaulat yaitu Pengadilan Negeri Bremen Jerman Barat. Tindakan pemerintah Indonesia saat itu dibenarkan oleh hukum Internasional, karena hukum Internasional menganggap bahwa selama tindakan Negara berdaulat (act of States) dilakukan diwilayahnya sendiri dianggap merupakan tindakan yang sah dan tidak melanggar hukum internasional. ${ }^{6}$

Jika dilihat dari segi promosi investasi, Indonesia dianggap sebagai Negara yang dinilai baik dalam melakukan promosinya, namun karena teralu banyak korupsi dan tidak stabilnya ekonomi, politik dan keamanan menyebabkan Indonesia mendapat nilai buruk dari potensi untuk meraih penanaman modal asing. ${ }^{7}$ Dari laporan tahunan yang disampaikan oleh World Invetment report dapat disimpulkan bahwa sebenarnya Indonesia sudah memberikan jaminan hukum yang cukup memadai bagi para inventor asing, tetapi permasalahannya justru terletak pada penegakan hukum, sehingga dianggap tidak menimbulkan adanya kepastian hukum bagi para investor. Bahkan dengan keyakinan tidak akan dilakukannya tindakan nasionalisasi terhadap perusahaan asing sebagaimana diatur

3 Ibid, Selain Invesment Guarantee Agreements yang memilki tujuan yang sama yaitu memebrikan perlindungan yang lebih baik dari Undang-Undang Penanaman Modal Nomor 25 Tahun 2007 adalah perjanjianperjanjian Investment Protection Agreements and Economic Coorperation Agreements.

${ }^{4}$ Convention on the settlement of Invesment Disputes Between states and National of other State.

${ }^{5}$ Tunduknya anggota Konvensi terhadap Yurisdiksi arbitrase ICSID harus dinyatakan kembali secara tertulis, sebagaimana diatur dalam Pasal 25 ayat (1) Konvensi, yang menyatakan : The jurisdiction of the shall extend to any legal dispute arising dorecly out of an investment, between a Contracting State )or any consitituent and a national or agency of a Contracting State designated to the Centre by thet State) and a national of another Contracting State, which the parties to the dispute consent in writing to submit to the Centre. Whwn the parties have goven their consent, no party may witdraw its consent unilaterally.

${ }^{6}$ Zander, Michael, 1976 Act of State doctrine, in Twentieth Century of Internasional Law, , hlm 409.

${ }^{7}$ United National Conference on Trade Development (UNCTAD), World Investment Report, 2002 
dalam Pasal 7 ayat (1) Undang-Undang Nomor 25 Tahun 2007 tentang Penanaman Modal, merupakan daya tarik tersendiri untuk menarik minat para investor asing.

Walaupun sebenarnya berdasarkan Pasal 7 ayat (1) di atas kemungkinan adanya tindakan nasionalisasi terhadap perusahaan asing tetap ada, namun pemerintah disini wajib untuk memberikan kompensasi terhadap perusahaan yang dinasionalisasi tersebut dengan jumlah, macam dan cara pembayarannya telah disepakati para pihak atau promt, adequate and effevtive. Selain terdapat dalam pasal diatas perlindungan terhadap nasionalisasi juga terdapat dalam Multilateral Investement Guaranty Agency, yang mengatur juga masalah kompensasi terhadap perusahaan asing yang dinasionalisasi yaitu harus promt, adequate and effevtive.

Bahwa stabilitas politik, keamanan dan penegakan hukum merupakan faktor utama yang harus diprioritaskan, agar penanaman modal asing segera pulih di Negara ini. Khususnya dalam hal penegakan hukum yang berkaitan dengan penyelesaian sengketa, terutama dalam pengakuan dan pelaksanaan putusan arbitrase ICSID. Umumnya dalam hal pengakuan dan pelaksanaan putusan arbitrase ICISID timbulnya permasalahan karena Negara-negara anggota Konvensi mengaturanya secara berbeda-beda. ${ }^{8}$ Berdasarkan latar belakang tersebut diatas maka penulis mencoba mengidentifikasikan permasalahanpermasalahan yang terjadi dan dijadikan bahan untuk diteliti dan dianalisis, yaitu sebagai berikut : Bagaimana peran dan tujuan arbitrase ICSID dalam kerangka penanaman modal di Indonesia?

\section{METODE PENELITIAN}

Sifat penelitian dalam penulisan ini adalah deskriptif yang dilakukan dengan pendekatan yuridis normatif. Jenis dan sumber data yang digunakan adalah data sekunder. Pengumpulan data dilakukan terutama dengan teknik studi dokumen (library research and online research) dengan menginventarisasi data sekunder yang diperlukan, baik berupa bahan hukum primer, sekunder maupun tersier, kemudian melakukan penelusuran sejarahnya dan sinkronisasi antar bahan hukum tersebut. Bahan hukum primer yang dipergunakan terdiri dari peraturan perundang-undangan terutama yang berkaitan dengan arbitrase dan penanaman modal asing. Bahan hukum sekunder yang akan digunakan digunakan antara lain berupa: karya ilmiah, hasil penelitian dan literatur yang berkaitan

${ }^{8}$ Moch. Basarah, Op Cit, hlm 144. 
dengan substansi penelitian. Bahan hukum tersier, yaitu bahan-bahan yang menunjang informasi bahan hukum primer dan sekunder, antara lain data dari surat kabar, jurnal, kamus, ensiklopedia.

\section{PEMBAHASAN}

\subsection{Peran Arbitrase ICSID Dalam Kerangka Penanaman Modal Di Indonesia}

Setelah Bank Dunia membentuk Konvensi Washington pada tahun 1965, yang melahirkan badan arbitrase ICSID (centre) setiap Negara anggota Konvensi menurut ketentuan Konvensi ini akan tunduk pada yurusdiksi Centre. Sehingga Negara yang dianggap melakukan tindakan melanggar hukum atau melanggar perjanjian terhadap investor asing, maka berdasarkan ketentuan Konvensi dapat diajukan kehadapan arbitrase ICSID. Seperti halnya sengketa yeng terjadi antara AMCO ASIA COORPORATION dengan PEMERINTAH INDONESIA, yang terjadi pada tahun 1980. Sengketa tersebut muncul karena pencabutan ijin penanaman modal oleh Ketua BKPM (Badan Koordinasi Penanaman Modal) terhadap AMCO ASIA COORPORATION. Pencabutan ijin tersebut oleh AMCO dianggap sebagi suatu tindakan yang merugikan mereka, pemerintah Indonesia dianggap telah melakukan perbutan melanggar hukum dan melanggar perjanjian. ${ }^{9}$

Para investor asing yang terdiri dari pengugat-pengugat AMCO CORPORATION PAN AMERICAN DEVELOPMENT LIMITED dan PT. AMCO INDONESIA relah mengajukan gugtan kepada Sekretaris Jenderal ICSID pada tanggal 15 Januari 1981. Permohonan gugatan mereka mengenai suatu sengketa hukum (legal dispute) yang terjadi dengan Republik Indonesia. ${ }^{10}$ Sengketa ini telah membawa Republik Indonesia sebagai salah satu Negara yang menjadi pihak di hadapan arbitrase ICSID, dikatakan demikian karena sengketa hukum penenman modal asing yang melibatkan Negara sangat sedikit. Di Asia saja baru dua Negara yang menjadi pihak di hadapan arbitrase ICSID, selain Indonesia yaitu Republik Srilangka. ${ }^{11}$ hlm 141.

${ }^{9}$ Moch. Basarah, 2007, Bunga Rampai hukum Perdata Internasional, Fakultas Hukum UNISBA, Bandung,

${ }^{10}$ Sudargo Gautama, 1986, Indonesia dan Arbitrase Internasioanal, Alumni, Bandung, hlm 2.

11 Tineke L.T Londong, Asas Ketertiban Umum dan Konvensi New York, Citra Bakti Bandung 1998, hlm 59. Sengketa-sengketa penanman modal asing yang sudah diselesaikan dan diputus oleh ICSID kurang lebih 46 kasusu dari tahun 1996 samapi tahun 2005. Dari tahun 1997 s.d 2005 terdapat kasus yang belum mendapatkan putusan, sedangkan 99 kasus suadah dalam bentuk rangkuman. Lihat mengenai hal in dalam www. Worldbank.org 
Jaminan hukum yang ditawarkan Pemerintah Indonesia sebenarnya sudah sangat memadai, namun karena keadaan Indonesia saat ini berbeda dengan keadaan masa lalu, mak diperlukan jaminan-jaminan hukum lainnya. Oleh karena itu, dalam kaitannya dengan hal ini, oleh perintah Indonesia. Karena jminan-jaminan inilah yang seharusnya ditawarkan oleh pemerintah Indonesia jika ada keinginan untuk menarik investor sebanyak-banyaknya. Sebagimana disarankan oleh Bank Dunia melalui Development Committe nya yang mengeluarkan Guidelines on the Traetment of Foreign Direct Investment kepada Negara-negara anggota Konvensi Washington agar menyediakan prinsip-prinsip pokok dalam menyusun ketentuannya masing-masing, sehingga investor tertarik. $^{12}$

Ketentuan yang dimaksud dalam Guidelines on the Treatment of Foregien Direct Invesment adalah ketentuan promosi bidang penanaman modal bukan ketentuan tentang mekanisme arbitrase ICSID. Karena Negara peserta Konvensi tidak dapat membuat ketentuan yang berhubungan dengan mekanisme atau tata cara artibitrase ICISID. Ketentuan arbitrase ICSID (Centre) harus bebas dari pengaruh system hukum nasional, arbitrase ICSID memiliki otonomi yang khusus sebagaimana diatur dalam Pasal 44 Konvensi yang pada dasarnya menytakan bahwa sengketa yang diselesaikan oleh Centre yang menimbulkan permasalahan prosedur dan tidak diatur dalam bagian ini atau dalam peraturan arbitrase atau aturan yang telah disepakati para pihak, maka Dewan Arbitrase yang akan memutuskan permasalahan tersebut. ${ }^{13}$

Dengan diajukannya sengketa melalui arbitrase ICSID, maka berdasarkan Psal 42 ayat (1) Konvensi para pihak mendapatkan jaminan bahwa mereka dapat mengunakan hukum acara sesuai dengan keinginan mereka. ${ }^{14}$ Hal tersebut sama pentingnya dengan masalah pelaksanaan putusan, dimana berdasarkan ketentuan in akan berada di bawah pengawasan pengadilan nasional dari Negara peserta Konvensi. ${ }^{15}$ Oleh sebab itu, dapat dikatakan bahwa peran yang diberikan oleh Konvensi kepada pengadilan nasional hanya dalam hal pengkuan dan pelaksanaan putusan arbitrase ICISID. Yang secara normative

${ }^{12}$ Moch. Basarah, Op Cit, Hlm 145

${ }^{13}$ Teks asli Pasal 44 Konvensi Washington, sebagai berikut: Any arbitration proceeding shall be coneducted in accordance with the provisioans of this Section and, except as the parties otherwise agree, in accordance with the arbitration Rules ineffect on the date on which the parties consented to arbitration. If any question of procedure arises is not convered by this Section or the Arbitration Rules or any rules agreed by the parties, the Tribunal shall decide the question.

${ }^{14}$ Pasal 42 ayat (1) Konvensi Washington, menyatakan sebagi berikut: The tribunal shall decide a dispute in accordance with such rules of law as may be agreed by the parties. In the absence of such agreement, The Tribunal shall apply the law of the Countracting State party to the dispute (including its rules on the conflict of laws) and such rules of international law as may be applicable.

${ }^{15}$ Delaume, George. R, Transnational Contracts, American Jurnal International Law, 1982, hlm 15. 
telah diaur Pasal 66 ayat (e) Undang-Undang Nomor 30 Tahun 1999 tentang Arbitrase dan alternative Penyelesaian Sengketa.

Selain hal tersebut pengadilan nasional sebenarnya tidak memiliki peran lain yang berhubungan dengan ketentuan Konvensi yang eksklusif dan memiliki otonomi khusus. Karena berdasarkan ketentuan Konvensi pengadilan nasional tidak dapat mengambil tindakan apapun yang mungkin bertentangan dengan sifat arbitrase ICSID yang eksklusif dan memiliki otonomi khusus. Dengan kata lain, pengadilan dari Negara anggota Konvensi sebaiknya menunda pelaksanaan proses perkara sebelum diselesaikan ICSID. Karena kemungkinan perkara tersebut merupakan yurisdiksi ICSID, pengadilan harus menahan diri dan mempertimbangkannya lebih lanjut serta mengijinkan para pihak untuk meyelesaikan sengketanya melalui arbitrase ICSID. ${ }^{16}$

Lebih jelas lagi mengenai hal tersebut dapat dikatakan bahwa pengadilan nasional tidak turut campur terhadap sengketa hukum yang menyangkut penanaman modal asing, karena sengketa ini merupakan keberadaan hukum nasional tidak begitu diperlukan dalam ruang lingkup penyelesaian sengketa penanaman modal asing. Karena peraturan mengenai mekanisme arbitrase ICSID telah diatur dalam secara komprehensif dalam Konvensi, peran hukum nasional hanya dalam hal pengakuan dan pelaksanaan putusan arbitrase ICSID. ${ }^{17}$

ICSID adalah merupakan sebuah organisasi yang lahir dari Konvensi Washington 1965, yang memilki tujuan untuk mempromosikan pembangunan ekonomi dunia melalui arus investasi dan perdagangan internasional yang lebih besar, dan menumbuhkan iklim saling mempercayai antara Negara (host State) dengan investor dalam meningkatkan arus penanaman modal. ${ }^{18}$ Dalam berbagai hal ICSID dapat dikatakan merupakan suatu organisasi yang unik dibidang alternative penyelesaian sengketa internasional, karena organisasi ini bibentuk untuk memenuhi kebutuhan tertentu pada masyarakat ekonomi global. Oleh karena itu, arbitrase ICSID dirancang sebagi penyeimbang keinginankeinginan antara Negara penrima modal (host States) dengan investor asing dan sebagi institusi yang menyediakan suatu mekanisme penyelesaian sengketa hukum yang efektif dibidang penanaman modal asing. ${ }^{19}$

\subsection{Tujuan Arbitrase ICSID Dalam Kerangka Penanaman Modal Di Indonesia}

\footnotetext{
${ }^{16}$ Moch. Basarah, Op Cit, Hlm 147

${ }^{17}$ Ibid,

${ }^{18}$ Smuty, Abby Cohen, Arbitration before thr International Cnetre for Settlement of Investment Disputes, Law Intelligence, Volume I, issue 02-March 2003, White \& case LLP, hlm 2

${ }^{19}$ Moch. Basarah, Op Cit, Hlm 147
} 
Berdasarkan data dari World Bank sejak berlakunya Konvensi Washington pada tahun $1966^{20}, 150$ kasus penenman modal asing yang diajukan antara tahun 1996-2005 ke artbitrase ICSID 49 kasus telah diberi putusan, dan 101 kasus masih menunggu putusan. Walupun anggota Konvensi sangat banyak, tetapi sengketa yang diajukan ke arbitrase ICSID tampaknya sangat sedikit. Hal tersebut menunjukan bahwa afektifitas dari suatu system penyelesaian sengketa tidak bisa diukur dengan hnya melihat dari banyaknya kasus yang telah diselesaikan. ${ }^{21}$ Adanya sengketa penanaman modal asing tergantung dari pelaksanaan kontrak yang telah disepakati oleh para pihak. Dalam penyelesaian sengketa, para pihak diwajibkan untuk mengunakan arbitrase sesuai dengan ketentuan Konvensi. Perjanjian ini menunjukan kesiapan suatu Negara yang terkait Konvensi untuk menerima arbitrase sebagai lembaga penyelesaian sengketa penanaman modal.

Kewajiban untuk mengunakan arbitrase ICSID dalam sengketa penanaman modal asning tentunya akan mempengaruhi pada pihak, baik Negara tuan ruamah (host State) meuoun investor asing khususnya untuk menghindari tindakan-tindakan yang mengarah pada pelanggaran perjanjian dan hukum internasioanal. Namun jika terdapat perbedaan pendapat, maka untuk menghindar dari konfik yang berkepanjangan biasanya dilakukan suatu metode cara damai misalnya dengan negosiasi atau mediasi. Adanya kewajiban menggunkan arbitrase ICSID dalam pananaman modal asing serta efektifitas prosedur badan arbitrase itu sendiri, dapat memberikan manfaat bagi para pihak agar terjalinnya suatu kerjasama dalam jangka panjang. Oleh karena itu, G. jaenike mengatakan bahwa sebaiknya Negara tuan rumah (host State) dan investor aasing dalam perjanjiannya agar selalu menyepakati untuk menggunakan arbitrase ICSID (Center) sesuai dengan ketentuan Konvensi Washington. ${ }^{22}$

Pendapat G. Jaenicke sebenarnya sejalan dengan tujuan dari Konvensi Washington yaitu untuk memlihara iklim investasi yang baik. ${ }^{23}$ Uga untuk kepentingan dari host State, sebagai Negara penerima modal dari luar negeri, sehingga dapat memberikan ketentraman kepada investor dengan tidak mengabaikan kepentingan mereka. Yaitu adanya perlindungan hukum yang wajar dengan diberikannya kesempatan untuk mengajukan segala persoalan ke hadapan arbitrase ICSID. Karena tujuan utma dari Konvensi adalah

\footnotetext{
${ }^{20}$ www.worldbank.org

${ }^{21}$ Jaenicke,G, 1990, The Prospects For International arbitration Disputes Between States and Private Enterprises, Comments on a paper by Professor U. Bauchez, dalam Soons,A.H.A International Arbitration Past and Prospects, Martinus Nijhoff Pub, hlm 155.

${ }^{22} \mathrm{Ibid}$, hlm 157

${ }^{23}$ Sudargo Gautama, 1996, Indonesia dan arbitrase Internasional, Alumni, Bandung, hlm 24
} 
memeberikan fasilitas bagi penyelesaian sengketa penanaman melalui arbutrase dan dengan cara damai. ${ }^{24}$

Sesuai dengan ketentuan Konvensi, dalam perjanjian penanman modal asing para pihak dapat melakukan pilihan hukum yang akan digunakan oleh arbitrase ICSID (choice of law $)^{25}$. Hukum yang dapat digunakan dalam sengketa penanman modal asing adalah hukum internasional dan hukum Negara penerima modal (host State). Diterapkannya hukum internasional dalam suatu sengketa penanman modal, akan mengandung arti yang sangat penting bagi para investor, karena mereka menginginkan investasinya dilindungi oleh hukum internsioanal. Namun, dilain pihak Negara penerima modal menginginkan investasi asing diatur oleh hukum naioanl mereka. Pilihan hukum para pihak ini jika diakitkan dengan kaidah-kaidah hukum perdata internasional, dalam rangka Konvensi Washington ini, tampaknya terdapat juga pengakuan terhadap otonomi para pihak dalam melakukan pilihan hukum bahkan sangat menghormati.

Namun jika melihat beberapa kasus penyelesaian sengketa penanaman modal, pada kenyataannya otonomi para pihak ini pernah juga dibaikan oleh dewan arbitrase ICSID. Seperti dalam kasus anatara PT AMCO melawan PEMERINTAH REPUBLIK INDONESIA. Seharusnya dalam kasus tersebut hukum yang digunakan adalah hukum yang telah disepakati oleh para pihak yaitu hukum Indonesia (host state), tetapi dewan arbitrase (tribunal) justru menggunakan hukum internasioanal. Sesungguhnya walaupun para pihak tidak melakukan pilihan hukum, dewan arbitrase harus menghormati ketentuan Konvensi dengan memberlakukan hukum host state. ${ }^{26}$

Oleh karena itu, berdasarkan keputusan dewan arbitrase ICSID tersebut, Pemerintah Indonesia mengajukan usul pembatalan putusan arbitrase berdasrkan alasanalasan sebagimana telah diatur dalam Pasal 52 ayat (1) Konvensi Washington, ${ }^{27}$ yaitu (a)

\footnotetext{
${ }^{24}$ Di dalam Konvensi Washington terdapat the rules of procedure for arbitration dan the rules of procedure for Conciliation..

${ }^{25}$ Pasal 42 ayat (1) Konvensi ICSID menyatakan : The Tribunal shall decide a dispute in accordance with such rules of law as may be agreed by the parties.

${ }^{26}$ Jaenicke, G, Op Cit, hlm 159 - Demikian juga keharusan penerpan hukum dari host states ini ditentukan oleh Pasal 42 ayat (1) Konvensi yaitu : "In the absence of such agreement, the Tribunal shall apply the law of the Contracting State party to the dipute (incuding its on the conflict of law) and such rules of international law as may be applicable.

${ }^{27}$ Pasal 52 ayat (1) konvensi Washington tentang permohonan pembatalan putusan ICSID, sebagai berikut : (1) Either party may request annulment of the award by an application in writing addressed to the seeretary General on one or more of the following grounds:

a) That the tribunal was not properly constituted

b) That the Tribunal has manifestly its powers

c) That there was corruption on the part of a member of the Tribunal

d) That there has been a serious depature from a fundamental rule of procedure

e) That there award has failed to state the reason on which it is based
} 
bahwa dewan arbitrase secara tegas telah melampaui batas-batas wewenangnya dengan tidak menggunakan hukum Indonesia dalam memeriksa dan memutuskan perkara. putusan dewan tidak disertai alasan-alasan yang mendasarinya dan terdapat kesalahan yang serius pada putusan yang bertentangan dengan prosedur yang sifatnya fundamental. ${ }^{28}$ Masalah yang sma juga terjadi terhadpa kasus anatra KLOCKNER INDUSTRIE, ANGLAGEN GMBH KLOCKNER BELGE S.A melawan PEMRINTAH UNI KAMERUN. Menurut ketentuan Konvensi, perkara yang keputusannya dimintakan pembatalan oleh salah satu pihak, maka sengketa baru dengan dewan arbitrase tersebut dianggap baru dengan dewan arbitrase yang baru. ${ }^{29}$

Kasus diatas sebenarnya merupakan salah satu kebrhasilan Negara berkembang dalam gugatan pembatalan terhadap putusan arbitrase ICSID. Permohonan pembatalan tersebut pada dasarnya disebabkan karena tidak puas dengan hasil putusan arbitrase. Hal ini merupakan suatu kenyataan yang disebabkan karena banyak klausul arbitrase yang disepakti oleh para pihak tidak dibuat dengan sebaik-baiknya atau karena tidak adanya kesepakatan terhadap berbagai masalah antar anggota Konvensi dengan investor. ${ }^{30}$ Negara berkembang juga dalam hal ini memperhatikan keprcayaan yang berlebihan terhadap investor asing sehingga hal tersebut menyebabkan pelaksanaan kontrak tidak sesuai dengan keinginan para pihak.

Dengan diperbolehkannya para pihak untuk mengajukan pembatalan terhadap putusan arbitrase ICSID berarti biaya penyelesaian sengketa akan bertamabah mahal, karena kasus yang sama dapat diulang beberapa kali sebagia kasus baru, dengan dewan arbitrase yang baru. Karena dalam Konvensi tidak ditentukan berapa klai batas pelaksanaan pengajuan yang dapat dilakukan oleh para pihak. Untuk itu, sebaiknya biaya penyelesaian perkara dapat lebih murah. Dan terhadap kasus yang diminya pembatalan agar diselesaikan dengan mekanisme terutama oleh tim khusus yang diberi wewenang untuk memberikan putusan. Dengan demikian kasus tidak perlu diulang atau dianggap sebagai kasus baru dengan dewan arbitrase yang baru, sebagiamana terjadi dalam kasus PT AMCO melawan PEMERINTAH REPUPLIK INDONESIA diatas. ${ }^{31}$

${ }^{28}$ Sudargo Gautama, Pengantar hukum Perdata Internasional Indonesia, BPHN, 1999, hlm 79

${ }^{29}$ Ketentuan tersebut dapat ditemukan dalam Pasal 52 ayat (6) Konvensi yang menyatakan :

If the award is annulled the disputes shall, at the request of either party, be submitted to a new tribunal constituted in accordance with a Section 2 of this Chapter.

${ }^{30}$ Kaoma Mwenda, Kenneth and Gobir, Nahu G., International Comercial Arbitration and the International Centre for Settlement of Investment Diputes, Zambia Law Journal No.30, 1998, hlm 115

${ }^{31}$ Moch. Basarah, Op Cit, Hlm 151 
Dalam kurun waktu empat puluh tahun tentunya arbitrase ICSID telah memilki catatan tentang penyelesaian sengketa penanaman modal asing yang ditanganinya. Banyaknya penggunaan klasul arbitrase ICSID dalam setiap perjanjian investasi (Bilateral Investment Treaties atau BITS) merupakan hal yang sudah biasa bahkan dapat diakatan menjadi meluas karena terdapat juga dalam kententuan-ketentuan hukum nasional dan perjanjian investasi lainnya. Adanya, klasul tersebut sebenarnya selain untuk mencegah terjadinya sengketa, juga sebagai tonggak (corner stone) bagi para pihak jika terjadi sengketa, karena tanpa klasul arbitrase sengketa mereka tidak dapat diajukan kehadapan arbitrase ICSID. Saat ini publisitas arbitrase ICSID sedang meningkat karena sengketasengketa yang sedang dan telah diselesaikan oleh arbitrase ICSID juga meningkat. Dalam hal ini masalahnya adalah apakah arbitrase ICSID selalu memberikan putusannya dengan efektif dan todak berat sebelah. ${ }^{32}$

Salah satu kekuatan dari arbitrase ICSID sebenarnya terdapat dalam Pasal 53 Konvensi yang ada pada dasarnya menyatakan bahwa putusan arbitrase mengikat para pihak dan tidak dapat dilakukan banding atau perbaikan lainnya, kecuali sebagimana diatur dalam Pasal 52 ayat (1) Konvensi. ${ }^{33}$ Oleh karena itu, untuk mempertahankan kehadiran Konvensi, bagaimanapun pengadilan nasioanl Negara anggota Konvensi tidak dapat meninjau ulang putusan arbitrase ICSID yang dapat dilakukan adalah permohonan pembatalan, interpertasi dan revisi terhadap putusan tersebut. Sedangkan dalam Pasal 54 Konvensi mengaur tentang pelaksanaan putusan arbitrase yang dapat dilakukan oleh setiap Negara anggota Konvensi. ${ }^{34}$

Ketentuan yang terdapat dalam Pasal 53 dan Pasal 54 diatas pada dasarnya telah membawa arbitrase ICSID pada kedudukan yang lebih baik dibandingkan dengan arbitrase lainnya. Karena dalam arbitrase ICSID, ketentuan Konvensi yang memberikan pengaturan bagi seluruh mekanisme penyelesaian sengketa, sejak para pihak menyatakan consent terhadap arbitrase ICSID sampai dengan berakhir sengketa yaitu pelaksanaan putusan arbitrase. Untuk itu, dapat diaktakan pengaturan hukum nasional mengenai arbitrase

\section{${ }^{32} \mathrm{Ibid}$,}

${ }^{33}$ Secara lengkap isi Pasal 53 ayat (1) Konvensi Washington tersebut adalah:

(1) The award shall be binding on the parties and shall not be subject to any appeal or to any other remedy except those provided for in this Convention. Each party shall abide by and comply with the terms of the award except to the extent that enforcement shall havw been syated pursuant to the relevan provisions of this Convention.

${ }^{34}$ Pasal 54 ayat (1) menyatakan sebagai berikut :

(1) Each Contracting State shall recognize an award rendered pursuant to this Convention as biding and enforce the pecuniary obligations imposed by that award within its territories as if it werw a final judgment of court in that State. A Contracting State with a federal constitutions may enforce such an award in or through its federal courts and may provide that such courts shall treat the award as if it were a final judgment of the cours of a constituent state. 
ICSID sangat terbatas, sperti halnya pengaturan tentan pelaksanaan putusan arbitrase ICSID di dalam Undang-Undang Nomor 30 Tahun 1999 hanya diatur dalam satu pasal saja yaitu dalam Pasal 66 ayat (e). dengan demikian peran yang diberikan oleh Konvensi terhadap pengadilan nasional sangat terbatas. Berbeda misalnya dengan arbitrase International Chamber of Commerce (ICC) atau arbitrase komersial lainnya yang didasarkan atas ketentuan Pasal V Konvensi New York 1958, yang mengatur tujuh alasan yang berbeda untuk digunakan oleh pengadilan nasioanal suatu Negara terhadap keberatan pelaksanaan putusan arbitrase, sehingga hal ini dapat menyebabkan berlarut-larut pelaksanaan putusan. ${ }^{35}$

Terhadap putusan arbitrase komersial yang pengakuan dan pelaksanaannya diatur berdasarkan Konvensi New York 1958, dapat dengan mudah ditoloak oleh salah satu pihak dengan mengemukakan adanya pelanggaran terhadap ketertiban umum Negara yang bersangkutan. Namun dalam konteks arbitrase ICSID, jika suatu Negara tidak mau mengakui dan melaksanakan putusan arbitrase berdasarkan ketentuan Konvensi, justru dianggap telah melakuakan pelanggaran terhadap Pasal 53 ayat (1) Konvensi. Terhadap pelanggaran ini investor dapat melakukan dua gugatan terhadap Negara tuan rumah yaitu (a) mengajukan gugatan sebagaimana dikenal dalam hukum national negara tuan rumah (host state) pada tingkatan diplomatic, atau (b) menyampaikan sengketa tentang putusan arbitrase yang tidak dapat dilaksanakan kepada Makamah Internasional yang memiliki yurisdiksi yang berhubungan dengan sengketa mengenai penafsiran dan penerpan Konvensi. ${ }^{36}$

Berdasarkan ketentuan Konvensi keputusan arbitrase ICSID harus diakui dan dilaksanakan, dengan demiian dlam hal ini doktrin kedaulatan yang dimilki Negara anggota Konvensi tidak dapat diberlakukan. Karena sesungguhnya dokrin kedaulatan Negara ini dapat mengahambat pelaksanaan putusan arbitrase secara paksa. Untuk itu, Negara peserta harus menganggap sama keputusan arbitrase ICSID itu sebagai keputusan yang telah dijatuhkan oleh pengadilan tingkat terakhir di Negara yang bersangkutan. ${ }^{37}$ Dan pihak yang akan melaksanakan putusan arbitrase di wilayah Negara peserta dapat menyampaikan kepada pengadilan atau instasi yang telah ditunjuj oleh Negara peserta

\footnotetext{
${ }^{35}$ Moch. Basarah, Op Cit,hlm 153

${ }^{36}$ Jaenicke, G, Op Cit, hlm 163

${ }^{37}$ Lihat Pasal 54 ayat (1) Konvensi
} 
untuk maksud tersebut, yaitu copy dari putusan yang telah dilegalisasikan oleh Sekjen ICSID. ${ }^{38}$

Agar dalam eksekusi putusan arbitrase ICSID tidak ada keraguan karena adanya doktrin kedaulatan dna pelaksanaan ketentuan tercantum dalam Pasal 54. Maka berdasarkan Pasal 54 Konvensi, ketentuan yang terdapat di dalam Pasal 54 tidak boleh ditafsirkan seolah-oleh pasal ini menyimpang dari ketentuan yang berlaku di Negara peserta berkaitan dengan imunitas Negara yang bersangkutan atau Negara sing lainnya. ${ }^{39}$

Dalam hal kaitannya dengan hak diatas, pengaturan tentang pengakuan dan pelaksanaan putusan arbitrase ICSID di Indonesia didasarkan oleh Pasal 3 UndangUndang Nomor 5 Tahun 1968 dan Pasal 66 ayat (e) Undang-Undang Nomor 30 Tahun 1999. Berdasarkan kedua Undang-Undang ini putusan arbitrase ICSID dapat dilaksanakan di Negara Republik Indonesia setelah memperoleh eksekuator dari Makamah Agung Republik Indonesia yang selanjutnya dilimpahakan kepada Pengadilan Negeri Jakarta Pusat. Tampaknya ketentuan tersebut telah mengikuti keinginan dari Pasal 54 ayat (3) yang mencantumkan bahwa eksekusi dari keputusan arbitrase ICSID akan diatur oleh hukum dari Negara diman eksekusi putusan arbitrase itu akan dilaksanakan. ${ }^{40}$

\section{PENUTUP}

\subsection{Simpulan}

1. Konvesi Washington 1965 telah memberikan peran yang sangat besar bagi Negaranegara berkembang khususnya Indonesia dalam meningkatkan arus penanaman modal. Dengan terbitnya Undang-Undang Nomor 25 Tahun 2007 dan UndangUndang Nomor 30 Tahun 1999 tentang arbitrase dan Alternatif Penyelsaian Sengketa, Negara-negara investor tidak perlu khawatir lagi akan terjadinya tindakan Pemrintah Indonesia yang melanggar hukum Internasional

2. Tujuan dari Konvensi Washington 1965 pada dasarnya adalah untuk mempromosikan pembangunan ekonomi dunia delalui arus investasi dan

\footnotetext{
${ }^{38}$ Pasal 54 ayat (2) secara lengkap menyatakan : (2) A party seeking recognition or enfordement in the the territories of a Contracting State shall furnish to a competent court or other authority which such State shall have designated for this purpose a copy of the award certified by the Secretary-General. Each Contracting State shall notify the Secretary_General of the designation of competent court or other authority fot this purpose and of any sebequent change in such designation.

${ }^{39}$ Secara lengkap ketentuan dalam Pasal 55 konvensi adalah: Nothing in article 54 shall be construed as derogating from the law in force in anya Contracting State relating to immunity of that State or any foreign State from execution.

${ }^{40}$ Selengkapnya isi Pasal 54 ayat (3) sebagai berikut: (3) execution of award shall be govered by the laws concerning the execution of judgments in force in the state in whose territories such execution is sought.
} 
perdagangan internasional yang lebih besar dan menumbuhkan iklim saling mempercayai antara Negara dengan investor dalam meningkatkan arus penanaman modal. Arbitrase ICSID yang dibentuk Konvensi Washington 1965 dapat dikatakan merupakan suatu organisasi yang unik dan dirancang sebagi penyeimbang keinginan-keinginan antra Negara penerima modal dengan investor asing dan sebagi institusi yang meyediakan suatu mekanisme penyelesaian sengketa hukum yang efektif dibidang penanaman modal asing.

\subsection{Saran}

Sejalan dengan perkembangan global juga perlu diatur keterlibatan pihak ketiga dalam proses arbitrase dengan mengakomodir konsep hak gugat organisasi, class action dan citizen lawsuit yang juga sudah diakui dalam berbagai peraturan perundang-undangan dan oleh pengadilan. Keterlibatan pihak ketiga atau amicus curiae penting sebagai bentuk kontrol publik khususnya pada sengketa yang berkaitan dengan kepentingan umum. Konsep ini dapat diterapkan pada kasuskasus arbitrase yang berkaitan dengan kepentingan publik seperti sengketa di bidang pertambangan dan lingkungan hidup.

\section{DAFTAR PUSTAKA}

Buku :

Delaume, George. R, 1982, Transnational Contracts, American Jurnal International Law.

Jaenicke,G, 1990, The Prospects For International arbitration Disputes Between States and Private Enterprises, Comments on a paper by Professor U. Bauchez, dalam Soons, A.H.A International Arbitration Past and Prospects, Martinus Nijhoff Pub.

Moch. Basarah, 2007, Bunga Rampai hukum Perdata Internasional, Fakultas Hukum UNISBA, Bandung.

Sudargo Gautama, 1999, Pengantar hukum Perdata Internasional Indonesia, BPHN. , 1996, Indonesia dan Arbitrase Internasional, Alumni, Bandung. , 1986., Indonesia dan Arbitrase Internasioanal, Alumni, Bandung

Smuty, Abby Cohen, Arbitration before thr International Cnetre for Settlement of Investment Disputes, Law Intelligence, Volume I, issue 02-March 2003, White \& case LLP.

Sunarjati Hartono, 1972, Beberapa Masalah Transnasional dalam Penanaman Modal asing di Indonesia, Bina Cipta, Bandung. 
Tineke L.T Londong, 1998, Asas Ketertiban Umum dan Konvensi New York, Citra Bakti Bandung.

Zander, Michael, 1976, Act of State doctrine, in Twentieth Century of Internasional Law.

\section{Jurnal :}

Kaoma Mwenda, Kenneth and Gobir, Nahu G., International Comercial Arbitration and the International Centre for Settlement of Investment Diputes, Zambia Law Journal No.30, 1998.

Peraturan Perundang Undangan:

Undang-Undang Nomor 25 Tahun 2007 tentang Penanaman Modal.

Undang-Undang Nomor 30 tahun 1999 tentang arbitrase dan alternative Penyelesaian Sengketa.

Konvensi Washington 1965. 